\title{
Heat production in municipal and industrial waste as revealed by isothermal microcalorimetry
}

\author{
Mohit Pushp ${ }^{1} \cdot$ Anders Lönnermark ${ }^{1} \cdot$ Mikael Hedenqvist $^{2} \cdot$ Peter Vikegard $^{3}$
}

Received: 19 May 2021 / Accepted: 20 October 2021 / Published online: 21 November 2021

(C) The Author(s) 2021

\begin{abstract}
Self-ignited fires at municipal solid waste (MSW) storage sites are relatively common. The minimization of the phenomenon of self-heating in the waste can reduce the risks for smouldering combustion. The purpose of this work was to develop a method that can be used to measure and characterize the heat production in MSW. The method is based on isothermal heat conduction microcalorimetry (IMC). The heat production in MSW was determined based on sampling from two sites in two different geographical locations in Sweden. Both the original waste and milled/homogenised waste were tested. The heat production was measured at different temperatures together with gas analysis using micro-gas chromatography. The activity in the waste, in terms of its heat flow, increased when the temperature increased up to $60^{\circ} \mathrm{C}$ and decreased at higher temperatures, e.g., 70 and $80^{\circ} \mathrm{C}$. The consumption of oxygen and the production of carbon dioxide, together with the heat production, indicated that aerobic metabolism was responsible for the heat production. This is further strengthened by the marginal heat production observed for ultraviolet treated waste. The results showed that IMC is a valuable tool for characterising the self-heating in municipal and industrial waste.
\end{abstract}

Keywords Municipal waste $\cdot$ Fire $\cdot$ Self-heating $\cdot$ Heat production $\cdot$ Microcalorimetry $\cdot$ Microorganisms

\section{Introduction}

Over two billion $\left(10^{9}\right)$ tonnes of solid waste, equivalent to a footprint of $0.74 \mathrm{~kg}$ per person per day, was generated globally in 2016 [1]. Considering population growth and the increase in urbanization, global waste generation is expected to be nearly double, approximately $1.4 \mathrm{~kg}$ per person per day, by 2025 [1]. The combustible fraction of the municipal and industrial waste can be converted into electricity and heat, which is most common nowadays when used as a fuel source for waste fired boilers.

To decrease the use of raw materials and scarce resources, there is also a need to increase the reuse and recycling of

Mikael Hedenqvist

mikaelhe@kth.se

1 Research Institutes of Sweden, Box 857, 50460 Borås, Sweden

2 School of Engineering Sciences in Chemistry, Biotechnology and Health, Fibre and Polymer Technology, KTH Royal Institute of Technology, 100 44, Stockholm, Sweden

3 Waters Sverige AB, Nanna Svartz väg 6A, 17165 Solna, Sweden materials. This leads to many and sometimes large temporary storage sites for waste. After the waste has been collected by the municipalities or private actors it may be stored for one to two months before it is combusted in waste fired power plants. Several fire events at waste storage sites have been reported [2-4]. Fires can lead to health issues, emissions to the environment, direct and indirect economic losses, disturbance of nearby activities and infrastructure, etc. $[5,6]$.

The phenomenon of self-heating or smouldering combustion is common [7]. Self-heating can occur due to chemical, biological, and physical exothermal processes. If the heat produced within the waste piles is not sufficiently dissipated, the temperature may rise until it reaches the auto-ignition temperature of the combustible material or combustible gases and fully developed fire can occur.

Methods available for the measurement of heat production in waste are scarce $[4,7-10]$. Techniques such as differential scanning calorimetry (DSC) and accelerated rates calorimetry (ARC) are popular for chemicals, explosives, and hazardous materials. In a conventional DSC, a small sample, typically $<30 \mathrm{mg}$, undergoes a controlled temperature increase to find a critical point at which a reaction takes 
place. The technique used in this work, isothermal microcalorimetry (IMC), provides an interesting replacement to DSC. The advantage of using IMC over DSC is its sensitivity. Due to higher absolute sensitivity in combination with a larger sample size, the detection limit of IMC is normally in the range of 1000-10,000 times higher than a conventional DSC, calculated per unit of sample mass [11, 12]. This means that reactions can be detected closer to waste storage temperatures, as opposed to conventional DSC measurements, for which accelerated conditions are required. Instead of studying the heat production, for example, at $140{ }^{\circ} \mathrm{C}$ using DSC, one can measure at $40^{\circ} \mathrm{C}$ using IMC, which is closer to the local hot spot temperature and general heating observed in waste piles during storage. There are also other methods, such as oven-basket methods, where the tests are performed at higher temperatures. Also, thermal imaging can be of use, however, a problem with this technique is that waste piles may be heated internally, while the surface is at ambient temperature.

Microorganisms normally produce heat flows in the range 1-10 pW per cfu (colony forming unit) [13], therefore, an isothermal calorimeter with a detection limit of $1 \mu \mathrm{W}$ can measure the heat release of as few as 10,000 active bacterial cells [14]. IMC has previously been used for assessment of safe storage conditions for such materials as soy sauce squeezing residue, fish meal, wood chips and forest residues $[11,15]$. IMC has also been applied to the measurement of heat production in biomass $[9,16]$.

There is a need for a reliable and sensitive method to measure heat production due to the overall chemical, biological and physical reactions in waste. There is also a need for a standardized method to assess the propensity for selfheating of different types of waste or different waste fractions. This work is aimed at initiating the development of both methods.

\section{Materials and methods}

\section{Types of waste}

Three types/mixtures of waste were used, abbreviated as: $\mathrm{W} 1, \mathrm{~W} 2$ and $\mathrm{W} 3$. These came from two waste handling sites. $\mathrm{W} 1$ and W3 came from a waste recycle and treatment company that handles municipal waste in the southern part of Sweden. W2 came from a municipal waste-handling company in a mid-sized Swedish city. W1 and W2 were mixtures of the combustible fraction of industrial waste, municipal solid waste, and organic waste. The combustible fraction of the municipal waste was used in this study, including diapers, food packaging, compost, rubber, crushed wood, textiles, liquid and powder paints and oil sludge from automotive industries etc. W1 and W2 were similar, and both are normally burned in waste fired boilers. W3 was a combination of a compost and a mixture of oil and water emulsion left over from automotive industries. W3 was mixed with $\mathrm{W} 1$ in specific ratios before it is burned in the waste fired boilers. All waste samples used in this study were representative of typical waste handled by the waste-handling companies.

Localized hotspots in the piles were observed during the collection of W2, while the ambient temperature was about $6{ }^{\circ} \mathrm{C}$ at the waste collection facility. W2 was collected after the metals had been sorted out using a magnetic separation process. The presence of non-magnetic metals, such as aluminium, could not be ruled out; however, after a visual inspection of the samples, no pieces of metals were observed.

\section{Sample preparation}

After the waste materials were received, they were stored at approximately $-15{ }^{\circ} \mathrm{C}$ and then defrosted at room temperature $\left(22^{\circ} \mathrm{C}\right)$ using air-tight plastic bags for a couple of hours before placing them in the calorimetric sample vessels for the heat flow measurement. Waste samples were enclosed in $20 \mathrm{~mL}$ air-tight sterilised glass ampoules for all IMC measurements. Silica sand with approximately the same total heat capacity as the waste sample was used on the reference side of the calorimeter. To calculate the heat capacity of the sample and the reference side, the specific heat of the silica sand and wastes (W1 and W2) was taken as $0.8 \mathrm{~J} \mathrm{~g}^{-1} \mathrm{~K}^{-1}$ and $1.4 \mathrm{~J} \mathrm{~g}^{-1} \mathrm{~K}^{-1}$, respectively [4]. The specific heat of the homogenised wastes was also measured by the Transient Plane Source (TPS) technique [17]. An average value of $1.35 \mathrm{~J} \mathrm{~g}^{-1} \mathrm{~K}^{-1}$ for both $\mathrm{W} 1$ and $\mathrm{W} 2$, obtained from four different tests, was in good agreement with the assumed value. The W1 and W2 samples were used as received from the waste storage facility regarding the moisture content, which was estimated to be approximately $30 \%$ on dry mass basis, as obtained after heating the sample in an oven at $105{ }^{\circ} \mathrm{C}$ for $24 \mathrm{~h}[18]$.

A scheme illustrating the industrial waste-route, and the samples used in this work is shown in Fig. 1. The waste samples, collected and received from the different sites, were heterogeneous. IMC measurements were therefore conducted on both heterogeneous and homogenised samples (milled samples). The heterogeneous wastes (W1 and W2) were homogenised by milling with a hammer mill $2.2 \mathrm{kWe}$, Model CF-158, manufactured by Cissonius GmbH, Germany. Both waste samples were milled 4-5 times to obtain particles that passed through a $5 \mathrm{~mm}$ square mesh. The waste was milled at a temperature of $2-4{ }^{\circ} \mathrm{C}$, to minimise a chemical and biological changes in the material. 


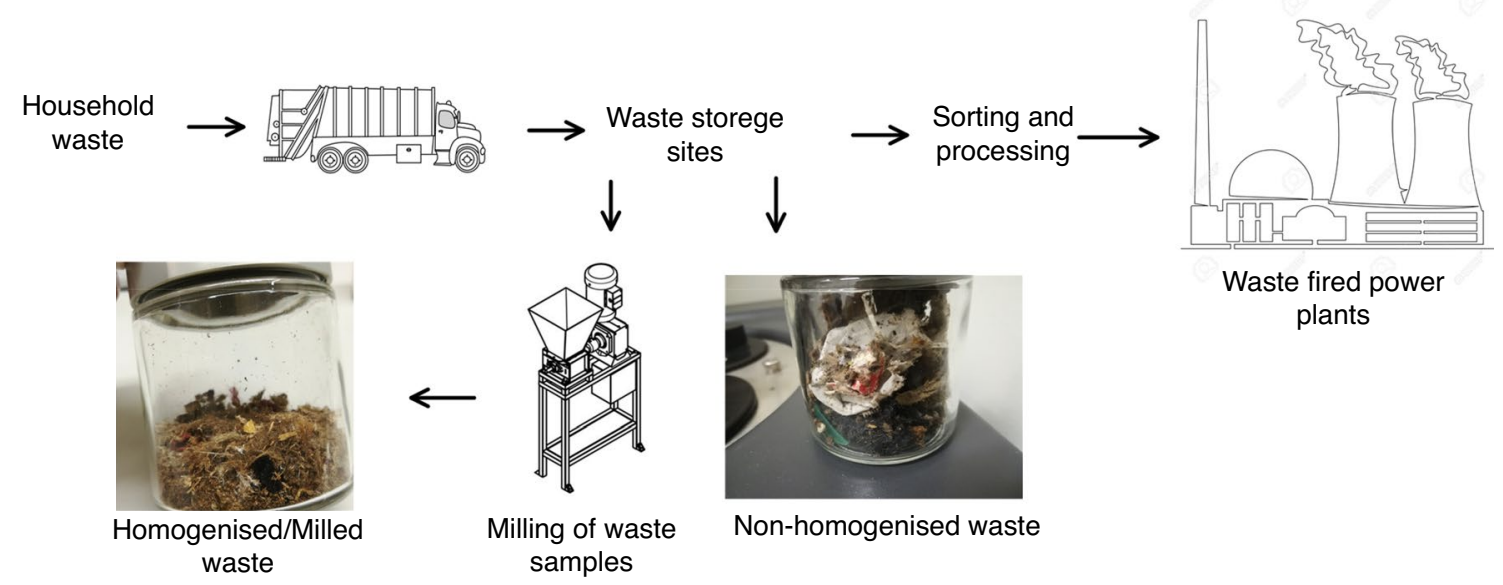

Fig. 1 Scheme illustrating the waste collection from households and all the way to the waste fired power plants and the waste samples (nonhomogenised and homogenised/milled) for the measurement of self-heating

W3 did not need to be milled because it was obtained as a slurry, however, the entire sample was stirred before the samples for IMC were collected.

\section{Test scheme and sample mass}

The heat flow from W1 and W2 was first measured with the samples in their original form. Later, measurements were conducted using homogenised samples. The samples were measured in duplicates, with a few exceptions. Supplementary Table $1 \mathrm{~S}$ (supplementary information) shows the masses of the W1 and W2 non-homogenised samples used in the calorimetric measurements. The masses of the homogenised samples are presented in Supplementary Table 2S.

\section{Isothermal microcalorimetry (IMC)}

The isothermal heat conduction microcalorimeter used in this work is commercially available as "Thermal Activity Monitor" or TAM Air, manufactured by TA instruments, US [17]. The calorimeters of the TAM instruments work according to the heat conduction or heat flow principle. During heat production or consumption (a thermal power), a heat flow between the thermally active sample and a temperature-controlled environment (a heat sink) is generated. The heat flow is typically measured by thermoelectric modules that separate a sample ampoule holder from the heat sink. A temperature difference over the thermoelectric module generates a voltage, which in turn is proportional to the heat flow. Calorimeters based on the heat flow principle are normally designed as twin or differential instruments. The sample side is mirrored by a reference side containing an inert material that matches the thermal properties of the sample, thus cancelling thermal fluctuation, which improves the signal stability. The temperature drift of the calorimeter is within $\pm 5 \mu \mathrm{K}$ over $24 \mathrm{~h}$. Calibration of the calorimeters were made with built-in electrical heaters, in accordance with the recommendation of the manufacturer.

The heat flow measurements were started after $45 \mathrm{~min}$ (time zero refers to the instant when the samples were placed in the calorimeter), ensuring that the samples were equilibrated at the calorimetric temperature. This was performed according to a procedure recommended by the manufacturer to minimize the uncertainty in the heat flow measurements that are related to the initial temperature difference between the sample and calorimeter. For comparison between the measurements, the heat flow and the cumulatively produced heat were normalised to the total sample mass.

\section{Sterilisation of waste W1}

The homogenised waste $\mathrm{W} 1$ was sterilised under UV radiation for some tests using an Atlas Suntest XLS + instrument with a xenon arc light source. The light intensity was $60 \pm 2 \mathrm{~W} \mathrm{~m}^{-2}$ within the $290-400 \mathrm{~nm}$ spectral band, $550 \pm 55 \mathrm{~W} \mathrm{~m}^{-2}$ within the $290-800 \mathrm{~nm}$ spectral band and $1300 \pm 130 \mathrm{~W} \mathrm{~m}^{-2}$ within the $290-3000 \mathrm{~nm}$ spectral band, according to the ISO 4892-2 standard. The waste was sterilised for $48 \mathrm{~h}$ at $22^{\circ} \mathrm{C}$ in an air-tight transparent plastic bag. After sterilisation the $\mathrm{W} 1$ waste was stored in an air-tight bag for a couple of hours prior to the IMC test conducted at $40{ }^{\circ} \mathrm{C}$.

\section{Gas chromatography}

The gases consumed or generated were measured by gas chromatography (GC, Agilent 490 Micro-Gas Chromatograph: TCD detector). The concentrations of the gases were 


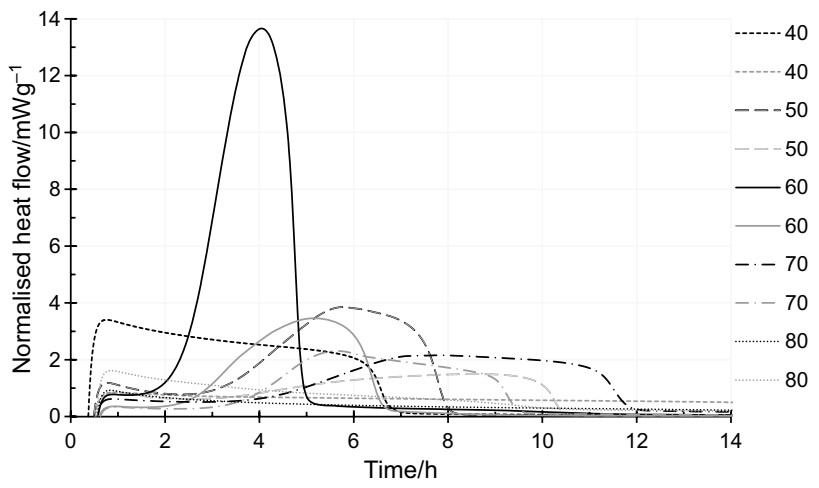

Fig. 2 Normalised heat flow measured at different temperatures for non-homogenised waste $\mathrm{W} 1$. Values to the right refer to temperature $\left({ }^{\circ} \mathrm{C}\right)$. The two sets of data at each temperature correspond to different sample masses (refer to Supplementary Table 1S)

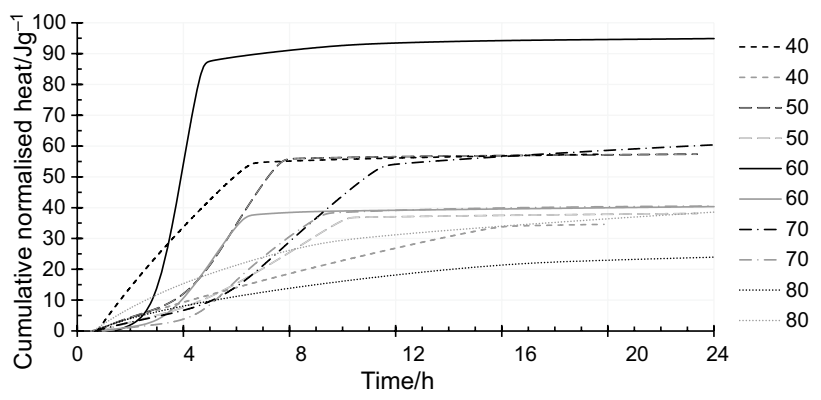

Fig. 3 Cumulative normalised heat from the samples in Fig. 2

analysed after the IMC measurements of the homogenised waste and ultraviolet (UV) treated waste (W1). Gas sampling was carried out by inserting a thin stainless-steel syringe ( $0.8 \mathrm{~mm}$ outer diameter), connected to a capillary $(0.8 \mathrm{~mm}$ outer diameter). One end of the capillary was always connected to the GC and the other end was inserted manually into the ampoule through the sealing cap. The GC was calibrated using ambient air between the two samplings. The detectable measurement ranges for the gases (vol \%) are given in the Supplementary Table 3S.

\section{Results}

\section{Results from non-homogenised waste samples}

Normalised heat flow $\left(\mathrm{mW} \mathrm{g}^{-1}\right)$ and cumulative normalised heat $\left(\mathrm{J} \mathrm{g}^{-1}\right)$ for the non-homogenised original waste $\mathrm{W} 1$ and W2, are presented in Figs. 2, 3; Supplementary Figures 1S and $2 \mathrm{~S}$. The heat flow measurements were conducted for $24 \mathrm{~h}$, although the normalised heat flow for $\mathrm{W} 1$ is shown for $14 \mathrm{~h}$ for clarity. No new peaks occurred beyond $14 \mathrm{~h}$. Notably, the thermal activity did not increase monotonically

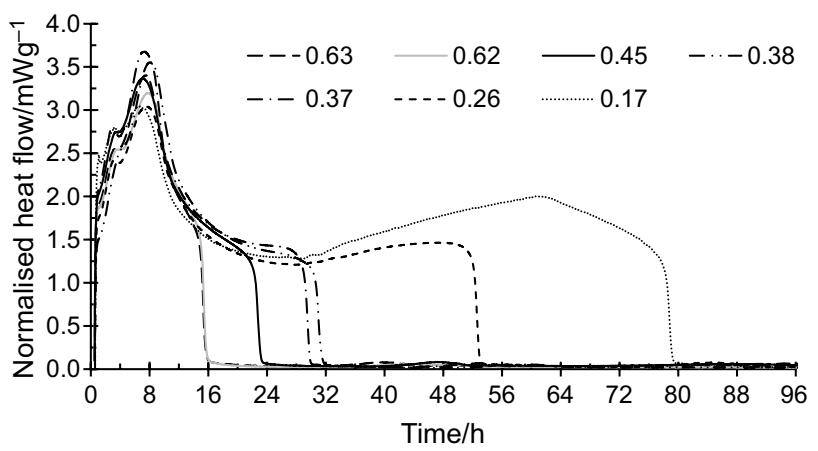

Fig. 4 Normalised heat flow for the homogenised waste $\mathrm{W} 1$ at $40{ }^{\circ} \mathrm{C}$. Values above the plot refer to sample mass $(\mathrm{g})$

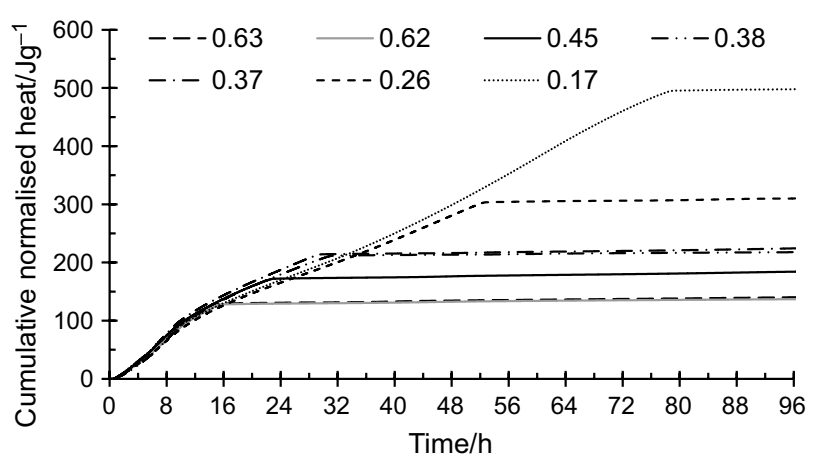

Fig. 5 Cumulative heat from the homogenised waste W1 using different sample masses at $40^{\circ} \mathrm{C}$

with temperature. In fact, on average, the W1 sample having the least thermal activity was observed at the highest temperature $80^{\circ} \mathrm{C}$ (Fig. 2); for $\mathrm{W} 2$ this occurred at $60{ }^{\circ} \mathrm{C}$ (Supplementary Figure 3S). As expected for the non-homogenised samples, the heat flow and cumulative heat showed poor repeatability. The test results showed that a significant amount of heat was produced in the waste samples. The poor repeatability, however, indicates that the crude industrial sampling for the calorimetric measurements is fraught with non-homogeneity. The results from the homogenised samples are presented in the next section.

\section{Results from tests with homogenised waste}

\section{Effects of sample mass}

Figures 4 and 5 show the normalised heat flow and cumulative heat, respectively, for the different sample masses of the homogenised waste $\mathrm{W} 1$, tested at $40{ }^{\circ} \mathrm{C}$. The heat flow-time evolution shows a major peak in the activity followed by a decrease towards zero or a shoulder ending with or without a second peak. The curves representing the samples were similar in the major peak region but deviated beyond that 
peak (after ca. $16 \mathrm{~h}$ ). The time at the drop towards zero correlated well in general with the sample mass, the lower the mass the later the decline. The drop towards zero could be seen from approximately $16 \mathrm{~h}$ for the $0.63 \mathrm{~g}$ sample to ca. $80 \mathrm{~h}$ for the sample with the lowest mass of $0.17 \mathrm{~g}$. The trend is also clearly visible in the cumulative heat values in Fig. 5.

\section{Effects of temperature}

The sample masses were within the range $0.5-0.7 \mathrm{~g}$ for the IMC measurements using wastes $\mathrm{W} 1$ and $\mathrm{W} 2$ at different temperatures. This mass range was chosen as a trade-off between the amount of head space oxygen available for the process, representative sampling, and to minimize the effect of sample size on the calorimetric results. The maximum heat was thus limited by the amount of oxygen and marginal heat was produced after the plateau between 80 and $90 \mathrm{~J}$ as shown in Figs. 6 and 7. Therefore, from this point the cumulative heat $(\mathrm{J})$ will be presented without sample mass normalisation. The normalised heat flow and cumulative heat produced by the samples $\mathrm{W} 1, \mathrm{~W} 2$ and $\mathrm{W} 3$ at the chosen temperatures $\left(45,50,60,70\right.$ and $\left.80^{\circ} \mathrm{C}\right)$ can be seen in Figs. 6, 7 and Supplementary Figure 3S-6S.

Figures 8 and Supplementary Figure 7S show comparisons of the time to reach $40 \mathrm{~J}$ for non-homogenised and homogenised $\mathrm{W} 1$ and $\mathrm{W} 2$ samples at $40-80{ }^{\circ} \mathrm{C}$. The cumulative heat at $40 \mathrm{~J}$ is roughly half of the maximum heat measured before reaching the limit determined by the amount of oxygen in the ampoule. The rationale for selecting $40 \mathrm{~J}$ is to overcome the uncertainties at least partially in the heat flow measurements. For example, if the comparison is made closer to the maximum amount of cumulative heat flow (for example 70 or $80 \mathrm{~J}$ ) the rate of the processes or the heat flow may be affected by the limited amount of oxygen in the ampoule. Although there is some scatter in the data, the comparison indicates that the time to reach $40 \mathrm{~J}$, which is inversely proportional to the rate of the processes (i.e., the micro-organism metabolic rate), was overall highest at the

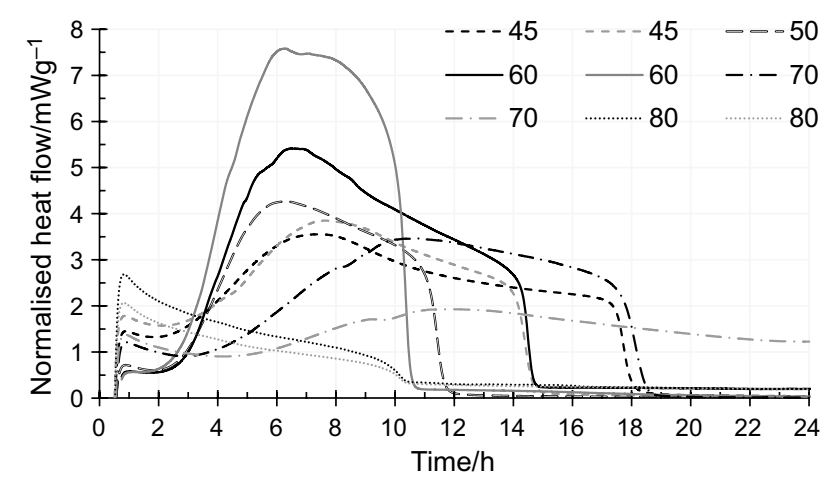

Fig. 6 Normalised heat flow from W1 after milling, tested at different temperatures $\left({ }^{\circ} \mathrm{C}\right)$

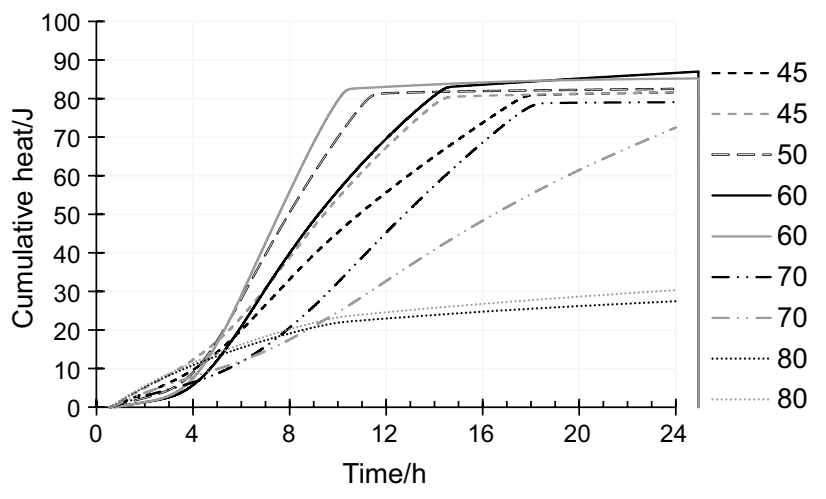

Fig. 7 Cumulative heat from the samples in Fig. 6

highest temperature $\left(80^{\circ} \mathrm{C}\right)$. The cumulative heat values at some temperatures were below $40 \mathrm{~J}$ for $\mathrm{W} 1$ and $\mathrm{W} 2$. The heat flow values corresponding to $40 \mathrm{~J}$ were obtained by extrapolating the cumulative heat with a straight-curve fit. The data also indicate that milling did not have a clear effect on the reactivity of the $\mathrm{W} 1$ samples.

\section{Off-gassing and effect of UV treatment}

Gases released and the amount of oxygen left in the ampoule headspace after the calorimetric measurements are shown in Table 1. In waste W2 the release of hydrogen was measured in addition to the other gases. This may be attributed to an exothermic event due to microbiological or chemical processes.

The homogenised W1 waste that was exposed to UV radiation showed a significantly lower heat flow and cumulative heat as shown in Figs. 9 and 10 compared to the unsterilized homogenised W1 waste shown in Figs. 6 and 7.

The GC measurements after the IMC measurement at $45{ }^{\circ} \mathrm{C}$ for all five UV treated W1 samples showed that oxygen was only marginally consumed. Indeed, the oxygen level after the measurement was approximately $20 \%$ (by volume)

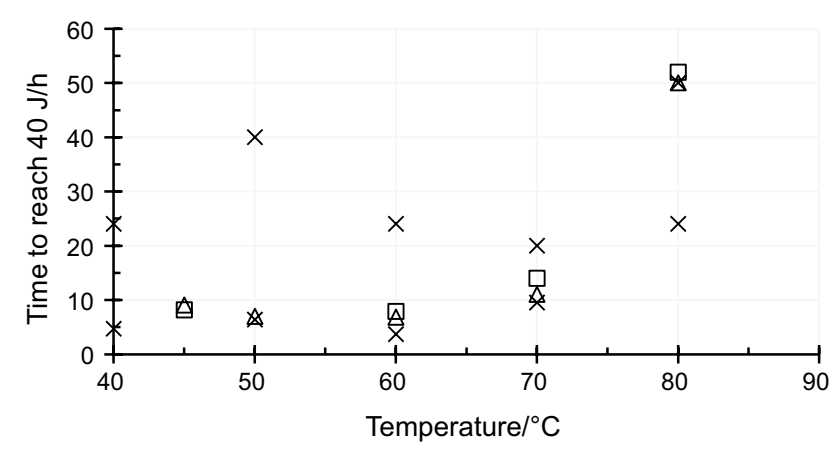

Fig. 8 Cumulative heat up to $40 \mathrm{~J}$ for W1. Cross symbols represent non-homogenised W1 samples. Square and triangle represent homogenised W1 samples 
Table 1 Gases released, and oxygen left in the ampoule for homogenised waste W1, W2 and stirred waste W3 at different temperatures

\begin{tabular}{|c|c|c|c|c|c|}
\hline $\mathrm{ID}^{\mathrm{a}}$ & $\mathrm{CO}_{2} / \mathrm{vol} \%$ & $\mathrm{O}_{2} / \mathrm{vol} \%$ & $\mathrm{H}_{2} / \mathrm{vol} \%$ & $\mathrm{CH}_{4} / \mathrm{vol} \%$ & Remarks \\
\hline W1_M_45 & 15,16 & 1,2 & $<0.1$ & $<\mathrm{DL}$ & \\
\hline W2_M_45 & 20,22 & $<0.1$ & $2.2,2.3$ & $<\mathrm{DL}$ & Note: $\mathrm{H}_{2}$ \\
\hline W3_45 & 4,5 & 13,14 & $<\mathrm{DL}$ & $<\mathrm{DL}$ & \\
\hline W1_M_50 & 11,16 & 1,2 & $<0.1$ & $<\mathrm{DL}$ & \\
\hline W2_M_50 & 19,20 & $<0.3$ & $1,1.5$ & $<\mathrm{DL}$ & Note: $\mathrm{H}_{2}$ \\
\hline W3_50 & 5,6 & 11,13 & $<\mathrm{DL}$ & $<\mathrm{DL}$ & \\
\hline W1_M_60 & 18,19 & $1.1,0.3$ & $<0.1$ & $<\mathrm{DL}$ & \\
\hline W2_M_60 & 18,20 & $0.2,1.3$ & $5.6,5.7$ & $<\mathrm{DL}$ & Note: $\mathrm{H}_{2}$ \\
\hline W3_60 & 13,19 & 2,3 & $<0.1$ & $0.1,2.5$ & Note: $\mathrm{CH}_{4}$ \\
\hline W1_M_70 & 15,17 & 2,3 & $<0.1$ & $<\mathrm{DL}$ & \\
\hline W2_M_70 & 15,16 & 2,3 & $<0.1$ & $<\mathrm{DL}$ & \\
\hline W3_70 & 7,8 & 10,12 & $<\mathrm{DL}$ & $<\mathrm{DL}$ & \\
\hline W1_M_80 & 2,3 & 17,18 & $<0.1$ & $<\mathrm{DL}$ & \\
\hline W2_M_80 & 4,5 & 15,16 & $<0.1$ & $<\mathrm{DL}$ & \\
\hline W3_80 & 5,6 & 13,14 & $<\mathrm{DL}$ & $<\mathrm{DL}$ & \\
\hline
\end{tabular}

DL, detection limit

${ }^{\mathrm{a}}$ Last number refers to temperature $\left({ }^{\circ} \mathrm{C}\right), \mathrm{M}$ refers to milled/homogenised samples

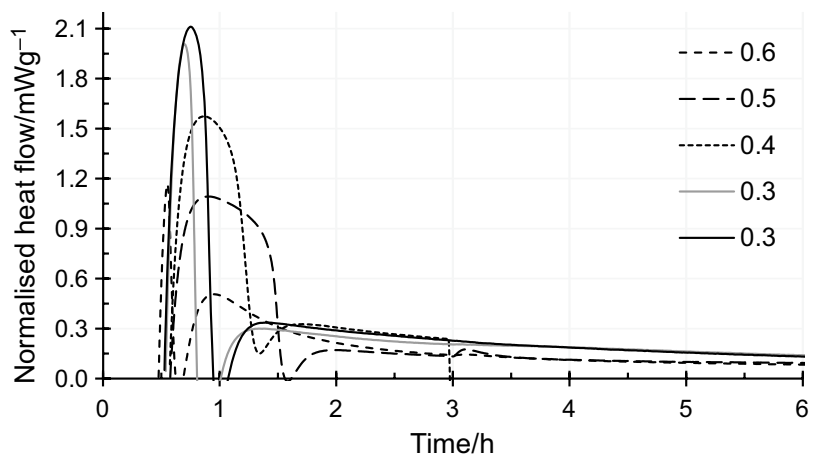

Fig. 9 Normalised heat flow from the UV treated homogenised waste W1 using different sample masses (in g) at $45^{\circ} \mathrm{C}$

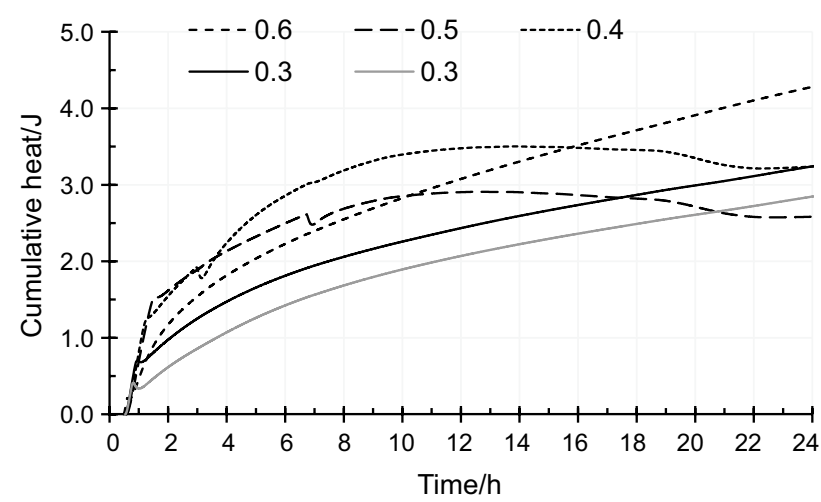

Fig. 10 Cumulative heat from the samples in Fig. 9
Table 2 Gases released, and oxygen left in the ampoule for the UVtreated homogenised waste $\mathrm{W} 1$.

\begin{tabular}{llllll}
\hline $\mathrm{ID}^{\mathrm{a}}$ & $\mathrm{CO}_{2} /$ vol\% & $\mathrm{O}_{2} /$ vol\% & $\mathrm{H}_{2} /$ vol\% & $\mathrm{CH}_{4} /$ vol\% & Remarks \\
\hline W1_M_ & 0.4 & 20.1 & 0.5 & $<\mathrm{DL}$ & \\
UV_45 $^{\text {UV }}$ & & & & & \\
\hline
\end{tabular}

Result is an average of five different samples

${ }^{\text {a }}$ Last number refers to temperature $\left({ }^{\circ} \mathrm{C}\right), M$ refers to milled/homogenised samples and UV for ultravoilet

and approximately $1 \%$ of both $\mathrm{CO}_{2}$ and $\mathrm{H}_{2}$ were detected. The GC results are shown in Table 2.

\section{Discussion}

The calorimetric results at the different temperatures indicate that the thermal activity was overall lowest at the highest temperature $\left(80{ }^{\circ} \mathrm{C}\right)$ for the homogenised $\mathrm{W} 1$ and $\mathrm{W} 2$ samples. The heat production was due to biological and/ or chemical processes. The sharp or gradual drop in the heat flows after the major peak for samples of different mass indicate that the process was limited by the available oxygen (Figs. 2, 4). The fact that the thermal activity was overall lowest at $80{ }^{\circ} \mathrm{C}$ indicates that the heat production was governed by mainly biological processes (Figs. 6, 7; Supplementary Figures $3 \mathrm{~S}$ and $4 \mathrm{~S}$ ). This result is further supported by the significantly lower heat production after the UV treatment of W1 samples [19] (Figs. 9, 10). For all the samples, the heat production per mol of oxygen consumed or mol of carbon dioxide produced was $500 \pm 20 \mathrm{~kJ} \mathrm{~mol}^{-1}$, which is comparable to the corresponding enthalpy of aerobic respiration $455 \pm 15 \mathrm{~kJ} \mathrm{~mol}^{-1}[20,21]$. At $80{ }^{\circ} \mathrm{C}$ or higher, significant reduction in the heat release is expected due to the unfavourable conditions for bacterial action [7, 22]. At $80{ }^{\circ} \mathrm{C}$, the cumulative heat was reduced by a factor of 2-4 compared to $50{ }^{\circ} \mathrm{C}$ or $60{ }^{\circ} \mathrm{C}$ (Figs. 7; Supplementary Figure 4S). Contributions due to chemical oxidation cannot be ruled out, although without the catalytic activity of the microorganisms this is more likely to occur at higher temperatures $[4,7,23,24]$.

The heat production rate in moist samples is likely different than in dry samples, considering the chemical or biological reactions in the presence of water. The evaporation of water from the sample contributes endothermically as the temperature in the sample goes from room temperature to e.g., $80^{\circ} \mathrm{C}$. The stabilization of the water vapour pressure in the sample ampoule when temperature is changed is not immediate. The saturation moisture content in the air in the $20 \mathrm{~mL}$ vial at $80{ }^{\circ} \mathrm{C}$, was approximately $6 \mathrm{mg}$. This means that a $0.6 \mathrm{~g}$ sample with $10 \%$ moisture holds approximately $60 \mathrm{mg}$ of water, which implies that at least $90 \%$ of the water will remain in the sample. Hence the sample moisture 
content should only change marginally during stabilization or thermal equilibrium. In absolute terms, the amount of water that would evaporate from the waste sample will be lower than mentioned above, because the water activity in the waste samples is probably below 1 (pure water is having a value of 1). If there is "free" water in the sample, it certainly contains various dissolved compounds, thus lowering the water activity. There may be a loss of heat from the sample in the initial phase of heating or thermal equilibration, however, in principle most of the heat should have been provided by the calorimeter as it has significantly higher specific heat in comparison to the waste samples. Nevertheless, the procedure recommended by the manufacturer has been followed and the initial 45 min of heat flow was not considered in the evaluation of the results.

A challenge in the measurement of heat production in waste is to obtain representative samples small enough to be evaluated in the calorimeter. The method suggested in this work is to mill and mix the sample waste thoroughly before the IMC analyses. There is a risk of missing specific parts of the material mixture that has a high propensity for self-heating, but such volumes of active material would be difficult to find without testing the full large-scale flow of waste material. The suggested method using homogenised material shows improved repeatability compared to testing the non-homogenised waste. Nevertheless, as observed in some of the data, even the homogenised samples can show scatter.

With respect to the different mechanisms for self-heating, the action of microorganisms is thought to play an important role of catalysing and thus accelerating decomposition of certain waste materials. It has been shown that metabolic rates and concomitant heat production rates in complex microorganism habitats in soil follow Arrhenius behaviour over the limited temperature range at which they are biologically active [25]. This work shows that the biological activity in the studied waste materials was lowest at $80^{\circ} \mathrm{C}$. Hence, from the point of view of self-heating, microorganisms can play an important role in a runaway situation at lower temperatures, and thereafter other reaction mechanisms can cause subsequent accumulation of heat causing local hot spots with the risk of self-ignition/smouldering.

\section{Conclusions}

Three different types of waste mixtures were tested with isothermal microcalorimetry for the assessment of heat flow. Specifically, the sample mass and the test temperature were varied.

The comparison of the heat flow measurements for homogenised waste and non-homogenised waste, indicated that the milling improved the heat flow repeatability.
For testing non-homogenised waste, the heat flows will be dependent on the selection of the material and the repeatability could be lower due to a larger variation in sampling for the calorimetric measurements.

The heat flows and the cumulative heat measured at 40 , $45,50,60{ }^{\circ} \mathrm{C}$ were generally higher in comparison to $80^{\circ} \mathrm{C}$. This indicates that heat production was primarily due to biological activity. The results are in accordance with reported data in literature, showing that below $70{ }^{\circ} \mathrm{C}$ the heat generation is mainly caused by aerobic microbial processes. The consumption of oxygen and the release of carbon dioxide indicated that aerobic metabolism dominated the heat production. Only marginal heat release was observed after the oxygen in the sealed ampoule was consumed. A significant reduction in the heat production after UV radiation supports the conclusion that microorganisms play an important role in heat production.

In addition to the microcalorimeter measurements, gas analysis has provided important information about the release or consumption of gases and can be used to assess reaction mechanisms. Hence, the combination of microcalorimetry and gas analysis is an effective method to assess the heat generation mechanisms in waste.

Supplementary Information The online version contains supplementary material available at https://doi.org/10.1007/s10973-021-11117-2.

Acknowledgements The work was funded by the Swedish Energy Agency (as part of the strategic innovation programme RE:Source), RISE Research Institute of Sweden, SYSAV, Tekniska Verken i Linköping, and Borås Energi \& Miljö. Their contributions are gratefully acknowledged.

Funding Open access funding provided by Royal Institute of Technology.

Open Access This article is licensed under a Creative Commons Attribution 4.0 International License, which permits use, sharing, adaptation, distribution and reproduction in any medium or format, as long as you give appropriate credit to the original author(s) and the source, provide a link to the Creative Commons licence, and indicate if changes were made. The images or other third party material in this article are included in the article's Creative Commons licence, unless indicated otherwise in a credit line to the material. If material is not included in the article's Creative Commons licence and your intended use is not permitted by statutory regulation or exceeds the permitted use, you will need to obtain permission directly from the copyright holder. To view a copy of this licence, visit http://creativecommons.org/licenses/by/4.0/.

\section{References}

1. Kaza S, Yao L, Bhada-Tata P, Van WF. What a waste: a global snapshot of solid waste management to 2050. World Bank, Washington, DC. License: Creactive Commons Attribution. 2018; CC BY 3.0 IGO. 
2. Hogland W, Marques M. Physical, biological and chemical processes during storage and spontaneous combustion of waste fuel. Resour Conserv Recycl. 2003;40:53-69.

3. Ibrahim MA, Alriksson S, Kaczala F, Hogland W. Fires at storage sites of organic materials, waste fuels and recyclables. Waste Manage Res. 2013;31:937-45.

4. Shimizu Y, Wakakura M, Arai M. Heat accumulations and fire accidents of waste piles. J Loss Prev Process Ind. 2009;22(1):86-90.

5. Ibrahim MA, Hogland W, Elmberg E, Lönnermark A, Persson H, and Nammari DR. Storage techniques for municipal solid waste, frequency of fires, and their related emissions. In: Proceedings of Venice 2010 - the third international symposium on energy from biomass and waste, Venice, Italy. 2010. p. 8-11.

6. Mikalsen RF, Lönnermark A, Glansberg K, McNamee M, Storesund K. Fires in waste facilities: challenges and solutions from a Scandinavian perspective. Fire Saf J. 2021;120:1-8.

7. Buggeln R, Rynk R. Self-heating in yard trimmings: conditions leading to spontaneous combustion. Compost Sc Util. $2002 ; 10: 162-82$

8. Jones JC. The self-heating and ignition of vegetation debris, 3: heat transfer measurements. Fuel. 1990;69:399-401.

9. Krigstin S, Wetzel S. A review of mechanisms responsible for changes to stored woody biomass fuels. Fuel. 2016;175:75-86.

10. Moqbel S, Reinhart D, Chen RH. Factors influencing spontaneous combustion of solid waste. Waste Manage. 2010;30:1600-7.

11. Wadsö L. Measuring chemical heat production rates of biofuels by isothermal calorimetry for hazardous evaluation modelling. Fire Mater. 2007;31:241-55.

12. Wadsö L, Gómez GF. Isothermal calorimetry for biological applications in food science and technology. Food Control. 2009;20:956-61.

13. Braissant $\mathrm{O}$, Bachmann $\mathrm{A}$, Bonkat $\mathrm{G}$. Microcalorimetric assays for measuring cell growth and metabolic activity: Methodology and applications. Methods. 2015;76:27-34.

14. Zaharia DC, Muntean AA, Popa MG, Steriade AT, Balint O, Micut R, Iftene C, Tofolean I, Popa VT, Baicus C, Bogdan MA, Popa MI. Comparative analysis of Staphylococcus aureus and Escherichia coli microcalorimetric growth. BMC Microbiol. 2013;13:171-171.

15. Murasawa N, Koseki H, Iwata $\mathrm{Y}$, Sakamoto $\mathrm{T}$. Investigation of accidents during storage caused by fermentation or oxidation from
SSSR and fishmeal using thermal analysis and Frank-Kamenetskii theory. Recycling. 2018:3:26.

16. Larsson I, Lönnermark A, Blomqvist P, Persson H, Bohlén H. Development of a screening test based on isothermal calorimetry for determination of self-heating potential of biomass pellets. Fire Mater. 2017;41:940-52.

17. Gustavsson M, Karawacki E, Gustafsson SE. Thermal conductivity, thermal diffusivity, and specific heat of thin samples from transient measurements with hot disk sensors. Rev Sci Instrum. 1994;65:3856-9.

18. Suurkuusk J, Suurkuusk M, Vikegard P. A multichannel microcalorimetric system. J Therm Anal Calorim. 2018;131(2):1949-66.

19. Gómez PL, Welti-Chanes J, Alzamora SM. Hurdle technology in fruit processing. Annu Rev Food Sci Technol. 2011;2:447-65.

20. Hansen LD, Macfarlane C, McKinnon N, Smith BN, Criddle RS. Use of calorespirometric ratios, heat per $\mathrm{CO}_{2}$ and heat per $\mathrm{O}_{2}$, to quantify metabolic paths and energetics of growing cells. Thermochim Acta. 2004;422:55-61.

21. Von SU, Gustafsson L, Larsson C, Marison I, Tissot P, Gnaiger E. Thermodynamic considerations in contructing energy balances for cellular growth. Biochimica Biophysica Acta (BBA) Bioenergetics. 1993;1183:221-40.

22. Fuller WS. Chip pile storage - a review of practices to avoid deterioration and economic losses. Tappi (United States). 1985;68:48-52.

23. Koenig A, Bar QH. Application of self-heating test for indirect estimation of respirometric activity of compost: theory and practice. Compost Sci Util. 2000;8:99-107.

24. Maheshwari R, Bharadwaj G, Bhat MK. Thermophilic fungi: their physiology and enzymes. Microbiology and molecular biology reviews. MMBR. 2000;64:461-88.

25. Barros N, Feijóo S, Hansen L. Calorimetric determination of metabolic heat, $\mathrm{CO}_{2}$ rates and the calorespirometric ratio of soil basal metabolism. Geoderma. 2011;160:542-7.

Publisher's Note Springer Nature remains neutral with regard to jurisdictional claims in published maps and institutional affiliations. 